\title{
Responsibility, Complexity Science and Education: Dilemmas and Uncertain Responses
}

Tara Fenwick, University of British Columbia

Fenwick, T. (2009). Responsibility, complexity science and education: Dilemmas and uncertain responses. Studies in Philosophy and Education, 28 (2), 101-118.

\begin{abstract}
While complexity science is gaining interest among educational theorists, its constructs do not speak to educational responsibility or related core issues in education of power and ethics. Yet certain themes of complexity, as taken up in educational theory, can help unsettle the more controlling and problematic discourses of educational responsibility such as the potential to limit learning and subjectivity or to prescribe social justice. The purpose of this article is to critically examine complexity science against notions of responsibility in terms of implications for education. First, themes of complexity science prominent in contemporary educational writing are explained. Then dilemmas of responsibility in complexity are explored, such as what forms and meanings responsibility can have in a 'complexified' perspective of education, how care for others is mobilised, and how desire can be understood. Analyses of ethical action grounded in complexity science are then examined, as well as theories of the ethical subject and participatory responsibility that are congruent with certain tenets of a complexity ontology. Finally, the possibility of an educational vision of responsibility animated by complexity theories is considered, drawing from related writings of Bai, Biesta, Derrida, Levinas and Varela.
\end{abstract}


Responsibility, Complexity Science and Education: Dilemmas and Uncertain Responses

\section{Introduction}

Complexity science is growing in popularity among educational researchers. Actually to refer to 'complexity science' or complexity theory as though it is a singular, monolithic body of knowledge is a gross error of misrepresentation: the complexity field by now embraces widely diverse theories such as general systems, cybernetics, chaos, deep ecological, enactivist and autopoetic theories. Nevertheless the term 'complexity science' will be used in this article, albeit cautiously, because it appears increasingly in educational writings. While its uptake is most evident in curriculum studies and K-12 pedagogical writing, it is beginning to appear in adult education and higher education (Cutright, 2001; Haggis, 2007; Karpiak, 2000) and has become popular in workplace education, particularly organisational development and training (Kauffman, 1995; Stacey, 2005).

A central problem in all of these uptakes, however, remains the question of responsibility - a question that arguably emerges at some point in any educational theorising. In fact educational writers such as Davis and Sumara (2006) as well as scientists such as Varela (1999) have attached notions of the good to their theorising of complexity in ways that raise questions about responsibility and ethics. However, derived as it was from biological and mathematical sciences, complexity science as a framework does not inherently offer constructs that speak to questions of educational responsibility. One may, as some have done, manipulate certain precepts of complexity science to adduce generalisations about responsibility from complexity's explanations about how elements in a system interact. But such analyses cannot legitimately answer important educational questions of how one should act or who is responsible to whom, nor can they address central_issues of educational responsibility: power, culture, ethics, social responsibility and democracy. One might argue, therefore, that to frame approaches to educational pedagogy, curriculum and policy in education using only complexity science is to either remain silent about educational responsibility or to project ethico-moral notions onto complexity science derived from some other discourse.

In fact, the radical ontology of complexity science troubles certain core assumptions of responsibility. Such troubling may be useful, particularly for the field of education where responsibility has become a prominent and, some might maintain, problematic discourse. When concepts central to responsibility such as agency, morality and intentionality are challenged by complexity concepts of flows, co-specification, self-organisation and emergence, the notion of 'responsibility' itself becomes reconfigured. In this respect analyses of ethical action grounded in complexity science (e.g. Bai, 2003; Varela, 1999) can be helpful, as are theories about how we might understand a 'call' to responsibility (Levinas, 1985), the uncertainties and contradictions in this call (Derrida, 1995), and participation in responsible action (Biesta, 2006). So while the 'ought' of education cannot be spoken through complexity science, its framework is useful in helping to articulate questions and dilemmas of educational responsibility. In this article I explore issues of responsibility in complexity science, then consider the possibility of educational responsibility animated by complexity theories, drawing from related writings of Bai, Biesta, Derrida, Levinas and Varela. 
If the responsibility of educators is to educate, to purposefully bring about learning, then we might ask: what understandings of learning and of purpose animate this bringing about? The question of educational responsibility has inspired much ethico-moral prescription both for the broad domain of pedagogy, practice and policy, and for the domain of educational research. McWilliam and Lee (2006) claim that education has been driven by twin fantasies fashioning its sense of purpose and therefore responsibility: on the one hand that it can ameliorate social disadvantage, and on the other that it can deliver transformative learning outcomes which will lead to improvement. Just what should be improved remains highly contested, argue McWilliam and Lee, but education historically has assumed a responsibility to socialise individuals to some social ends through learning - which in turn is assumed to be good. Whether intended outcomes of this learning are related more to building autonomous self-actualised individuals, imagination, civil society, a productive economy, or equity and justice, the central point of educational responsibility has been principally fixed upon building (and disciplining) particular kinds of subjects. Within this primary activity of 'shaping subjectivities' (Osberg and Biesta, 2007a), the educator's responsibility is:

to create learning environments (curricula) in which educational goals (regardless of how vaguely defined) can be met. If the outcomes are not met (for whatever reason), the educator is considered to have failed in his or her responsibility to educate. (Osberg and Biesta, 2007a, p. 3)

Of the problems with current conceptions of educational responsibility, Osberg and Biesta (2007a) draw particular attention to the delimiting of learning that occurs when education defines itself as teleologically riveted towards particular outcomes. That is, the kinds of meaning that can 'emerge' in a classroom become limited by what is in effect a process of 'planned enculturation' (p.3). A second problem mentioned briefly by Osberg and Biesta is the adjudication of competing cultural visions claiming centrality in educational responsibilities for cultural transmission and citizenship development. In particular, in recent years the increasing uptake of critical traditions of sociology, curriculum and pedagogy have engendered a strong discourse of social responsibility in education. The ascendance of this discourse as a central frame for discussions of educational responsibility might be argued to represent a distinct third problem. Perspectives within the social responsibility discourses in education are diverse and contested (Wildemeersch, et al., 2000). Many are derived from a critical cultural analysis of systems. This analysis points to structural inequities and neo-liberal market ideologies that generate individualism, hyper-competition, oppression and environmental degradation. The educational position is often constituted as one of social justice: another contested concept but often associated with generating political awareness, resistance and democratic transformation. For example, in the UK Ian Martin, like others trying to revive a radical agenda, calls educators to mobilise themselves and others around social transformation:

The central purpose of critical and creative adult education, as distinct from the current hegemony of lifelong learning, should be precisely to challenge this depoliticization of politics and to raise such matters as issues for urgent democratic deliberation and debate. (Martin, 2003, p. 569) 
In this social change tradition of education, social responsibility and active civic participation have been widely accepted as self-evident goals achieved through learner empowerment, community development, citizen and global education, or participatory literacy. Social responsibility is often cast nobly, even messianically, in opposition to educative goals of assimilation: accommodating people to a global economy, increasing their skill performance and reinforcing dominant discourses of individualism, flexible adaptation, entrepreneurism and selfinterest. Pedagogical concerns of social responsibility are dedicated to raising individuals' awareness and mobilising their participation in issues of social justice, inclusion and equality, environmental sustainability, human rights, and so forth. However, in such educational discourses including critical, feminist, anti-racist and other emancipatory pedagogies, a danger pointed out repeatedly is the presumption of the emancipator pronouncing a vision of democracy for others. There is a problematic revolutionary zeal and moral imperative operating that can become controlling, and lead to undesirable consequences.

Complexity science, particularly in its current uptake in educational writings (Bai, 2003; Davis \& Sumara, 2005, 2006; Doll et al., 2005; Haggis, 2007; Laidlaw, 2005; Osberg, 2005) appears to offer more generative alternatives for imagining educational responsibility with its emphasis on participatory epistemology, mindful engagement, and disruption of certainty. In fact, complexity in education may open new ways for rethinking responsibility and interrupting the more controlling, moralistic discourses promoting social responsibility in education: 'We cannot avoid responsibility because we cannot avoid responding in some ways to each and every person and situation we encounter and thereby affecting the world in some ways' (Bai, 2003, p. 9). At the same time, however, complexity science does not necessarily speak to issues of power relations, desire, positional interests, and other dynamics of socio-cultural human systems that figure significantly in understanding issues of responsibility and ultimately, of education. Therefore it seems fruitful to explore questions of responsibility alongside complexity science in its educational uptakes.

There is danger in applying any body of theory to an educational problem, an endeavour that can become funnelled into prescribing pedagogical method. Similarly, educative concerns with their moral implications and inherent impulse to act for change should be brought to complexity science with caution, or important elements of socio-cultural systems and educational practice that lie outside the explanatory foci of complexity may disappear from discussion. These caveats must be foregrounded in considering complexity science alongside the philosophical problem of responsibility as it is taken up in educational practice/debates. In the present discussion, my approach is to focus on picking apart issues raised by each domain for the other. That is, I am interested in the questions and possibilities that considerations of responsibility bring to complexity science in an educational context, as well as questions opened by the reversal. The strategy I employ is to read complexity science against responsibility theory, and to read the ensuing questions with the educational impulse. From a reading against/reading with position, I hope to avoid resolutions, unsettle applications, and to hold open the aporias that will sustain perpetual uncertainty and inquiry among these domains.

Responsibility, ethics and education 
Before exploring new visions for educational responsibility offered by these themes of complexity science, it is important to delineate more precisely what is meant by responsibility and what issues it bears. Conceptual discussions of responsibility are wide-ranging, from causal (who caused the problem) to consequential responsibility (who takes the blame); and from attributed (who is held accountable) to distributed responsibility (how accountability is apportioned among agents). In the context of education and in particular, the context of social responsibility as an educational purpose driving curriculum and pedagogy, the focus is upon moral responsibility that is felt and enacted. The pedagogical questions tend to rally educators' commitment to curricula oriented to particular sites of moral responsibility for social issues (solidarity with oppressed peoples, civic participation, democratic action for equity, resistance to market globalisation, environmental sustainability, and so forth) and to focus on how best to develop this responsibility in students. However in the present discussion I step back from the prescriptive to ask critical questions about how moral responsibility can be understood in terms of what comprises educational responsibility: that of the educator for learners in particular, and community and society in general through pedagogical practice.

Moral responsibility invokes notions of both obligation and moral decision-making. Obligation calls forth a sense of duty to care for self and others extending beyond one's own self-interest, and accountability to others for one's actions. Others in this sense can be interpreted broadly: other human beings, other collectives such as community or national interests, authorities, tradition, animals or non-sentient beings of the natural universe, concepts or ideals. Moral decision-making to acknowledge and act upon one's responsibilities incites questions about the conception of the 'good', the attendant criteria or 'laws' that should guide individual action, and the extent of one's freedom to choose. Within all of this, as Gibbs (2000) points out, some view a distinction between responsibility as felt and responsibility as acted. For example in education, there may be emphasis on raising learners' awareness of and personal commitment to civic responsibilities, as well as guiding them to enact their particular responsibilities as students.

In the field of ethics, critical debates have long swirled around the questions: Who is responsible to whom, for what, and to what extent? Responsibility has been developed within a tradition of rational philosophy as a question primarily of ethical decision-making, invoking issues of universal laws and the problem of the contingent particular situation, as well as bonds and obligations that inhere in an individual, conceived as autonomous, intentional, and capable of acting independently of others. However Levinas (1981) and educational philosophers who have taken up his conception of the ethical subject (e.g. van Manen, 2001; Biesta, 2006) have begun from a basic critique of the assumptions embedded in this rational tradition. Levinas (1981) views the subject as coming into presence through actively 'being': which is 'otherwise than being'. First, Levinas counters the view that individuals act and reason as autonomous agents, and stresses the intersubjective relationships that enmesh human beings with one another beyond their conscious intention or rational application of moral principles. Second, Levinas dismisses the act of rational ethical decision-making, arguing that ethical responsibility is moved by and enacted within moments of connection, participation with others that calls forth response. Derrida (1995), in his meditations on responsibility extending the work of Levinas and Kierkegaard, shows the problem of considering just who or what is Other when all are enmeshed, and the conflicts between responding to the Other's call, the community expectations, and the other Others excluded by a particular response. 
These considerations shift the definition of responsibility from notions of felt duty to the active responding to others, broadly conceived, within complex webs of connection. A focus on response turns attention away from defining what is the good, and what ethical laws should guide action, toward questions about how response is excited, by whom or what, what forms it takes, and what are its consequences. Thus, responsibility is not necessarily a modernist or utterly rational construct, but can be a phenomenal and relational dynamic whose logic is not necessarily irreconcilable with complexity science.

\section{Complexity science and education}

To be clear about the understandings informing this discussion I have selected themes that, for me, distinguish a complexity perspective: emergence, flows and relations, uncertainty, selforganisation, and interconnected diversity. It is not my intent here to debate details of complexity theor(ies), nor to defend complexity science's explanation of reality, cognition, knowledge and subjectivity. Nor do I attempt to present a comprehensive or monolithic view of complexity science, which is by now represented with wide-ranging degrees of nuance and rigor in the social sciences as a heterogeneous family of theories. Instead I draw on those themes that seem to have most frequent uptake among educational writers such as Davis and Sumara (2006), Davis, Sumara and Luce-Kepler (2000), Haggis (2007), Karpiak (2000), Laidlaw (2005), and Osberg (2005), who themselves draw upon complexity theories of, among others, Capra (1996), Prigogine (1997), and Waldrop (1992). (For a useful explanation of further concepts in complexity science, consult the Complexity and Education glossary at the University of Alberta: http://www.complexityandeducation.ualberta.ca/glossary.htm)

The key theme is emergence, the understanding that in (complex adaptive) systems, phenomena, events and actors are mutually dependent, mutually constitutive, and actually emerge together in dynamic structures. That is, the nature of the system as well its elements and their relationships both human and non-human - emerge through the continuous rich and recursive interactions among these elements. No clear lines of causation can be traced from these interactions to their outcomes, because at any given time among all these interconnections possibilities are contained in the system that are not visible or realised. This means, among other things, that humans are fully nested within and interconnected with many elements of the systems comprising them and in which they participate. They are not considered to be autonomous, sovereign agents to whom responsibility can be attributed or extracted. The following paragraphs elaborate further dynamics of emergence from a complexity science perspective.

One characteristic of the ongoing interactions in complexity is the process of 'structural coupling' (Maturana and Varela, 1987). That is, when two actors or systems coincide, the 'perturbations' of one excites responses and changes in the structural dynamics of the other, which couple with and alter the elements engaging with it in a new unity. An educational project, for example, is a collective activity in which interaction both enfolds and renders visible the participants, the objects mediating their actions and dialogue, the problem space that they define together, and the emerging plan or solution they devise. As each person contributes and responds within the activity, she changes the interactions and the emerging object of focus; other participants are changed, the relational space among them all changes, and the looping-back 
changes the contributor's actions and subject position. This is 'mutual specification' (Varela, Thompson, and Rosch, 1991), the fundamental dynamic of systems constantly engaging in joint action and interaction. The resultant coupling changes or 'co-specifies' each creating a new transcendent unity of action and identities that could not have been achieved independently by participants. These emergences are recursive, continuing to elaborate what is present and what is possible in the system. Out of these continuous and non-linear interactions emerge dynamic structures that exceed their parts. Osberg and Biesta (2007b) call this 'strong emergence': conditions where what emerges is more than the sum of its parts, and therefore not predictable from the 'ground' it emerges from. Davis and Sumara (2005) offer detailed explanations of the science implicated in strong emergence, which have been illuminated by analytic tools such as fractal geometry.

fractals are generated through recursive processes - in contrast to Euclidean forms, which are built up through linear sequences of operations. At each stage in a recursive processes, the starting point is the output of the preceding iteration, and the output is the starting point of the subsequent iteration. Every stage, that is, is an elaboration, and such elaborations can quickly give rise to unexpected forms and surprising complexity. The sorts of recursive functions that are used to generate fractals are also non-compressible. There are no shortcuts to their final products. A person interested in the eventual product of a fractal-generating function must allow it to unfold. (Davis \& Sumara, 2005, p. 309)

Further, what emerges - whether knowledge, identities, practices or symbols - is specific to the system in which it emerged, and therefore cannot exist as an object that can move to another system. In the educational uptake of complexity science, the notion of flows and relations among things, rather than the things themselves, are emphasised (e.g. see Davis 2004; Davis \& Sumara 2006; Karpiak 2000; Laidlaw 2005). The focus is not upon isolated actors and objects foregrounded against some contextual backdrop, but on the dynamic, nonlinear actions and connections flowing between all these parts. That is, complexity science interrupts the natural tendency to seek clear boundaries between figures and grounds, and focuses on the relationships binding humans and non-humans (e.g., desks, cell phones, bacteria, buildings, language, smells, memories) together in multiple fluctuations in complex systems. Thus, argue complexity theorists, the boundaries between self and non-self (nature as well as society) are actually more permeable and the flow between them more continuous than we might be prepared to accept.

Related to this emergence of novel forms through these non-linear dynamics of interaction, is the complex system's continuous state of uncertainty and surprise, a condition that Prigogine (1997) famously described as 'far from equilibrium'. What is happening within and among systems is affected by many active micro-interactions and improvisations that cannot be tracked, whose outcomes are affecting one another to form continually emerging phenomena. Uncertainty is a central structural principle within these dynamic processes. Actions, choices and meanings that will emerge are unpredictable. In other words so many things are going on all at once and so many new possibilities emerging that there can be no reduction of the system's patterns to causes and effects. More to the point, among the possibilities emerging at any given time in the system, it is impossible to predict which will most influence what will happen next. This is partly because the principles influencing the system's choices for action and knowledge are not present in the system's present patterns or its parts - they emerge too, in the dynamic processes of emergence. Therefore, the future of the system can be nowhere evident in the 
patterns of the present system. This fundamental property of uncertainty naturally poses challenges for educational planning, governance, application of routines or laws including ethical laws, and issues of accountability and responsibility.

One consequence of this disequilibrium is continuous adaptive change. A complex system is self-modifying - sensitive and responding to changes within it and around it - in constant dialogue with its environment. Its many components are always alive, always interacting creatively with parts directly around them. These interactions form patterns all by themselves they do not organise according to some sort of externally imposed blueprint - so complexity theorists describe such systems as self-organising. That is, through the ongoing processes of recursively elaborative adaptation, the system can maintain its form without some externallyimposed discipline or organising device, such as lesson plans, teachers, and class schedules. What Davis (2004) calls a 'transcendent collectivity' (p. 151) with an identifiable unity and coherence emerges through the bottom-up interactions of multiple agents. New novel forms of order are continually emerging, but the system usually will continue to maintain its identity except in the condition of severe perturbation.

The key to a healthy system - able to emerge into a resilient unity and adapt creatively to changing conditions -- is interconnected diversity among its parts. A human body, for example, relies on highly specialised subsystems that not only each respond to different circumstances and different needs, but also have learned to co-habitate and communicate with one another. Other dynamics required in self-organisation are, according to Davis (2004), redundancy or sufficient overlap among the agents (such as shared texts, language, interests) to enable the interactions that will give rise to the system, a means by which agents can affect one another such as proximity, and a decentralised, distributed form of organisation. When these elements are present, a system can emerge with a distinct integrity without top-down control, even as it is continually interacting with the systems surrounding it and embedded within it. As Hesoon Bai (2001) writes, 'Changes are the result of our interpenetrating the world' (p. 26), more than of our conscious intentional action to do something.

Overall, in complexity science knowledge and action are understood as continuous invention and exploration, produced through relations among consciousness, identity, action and interaction, objects and structural dynamics. New possibilities for action are constantly emerging among these interactions of complex systems, and cognition occurs in the possibility for unpredictable shared action. Knowledge and therefore responsibility cannot be contained in any one element or dimension of a system, for knowledge is constantly emerging and spilling into other systems. No actor has an essential self or knowledge outside these relationships: nothing is given in the order of things, but performs itself into existence. In educational applications of complexity science, attention is drawn to the relationships among learners and the environment. Learning is defined as expanded possibilities for action, or becoming 'capable of more sophisticated, more flexible, more creative action' (Davis, Sumara, \& Luce-Kepler, 2000).

These principles of emergence and interpenetration of people and objects, the flows and relations connecting them, the uncertainty arising from their many interactions and the self-organisation emerging from the system's interconnected diversity and creative adaptations are helping to challenge conceptual subject/object splits. Complexity science refuses the notion that universal 
laws can be applied to systems of activity, that autonomous individuals are separated from Others, that they act according to independent choices and rational intentions, and that therefore they bear personal moral responsibilities that govern their choices for action. These notions point towards a complexified view of responsibility as woven into fully embodied nets of ongoing action, invention, social relations and history in complex adaptive systems.

\section{The problem of responsibility in complexity science}

Nonetheless, it becomes immediately apparent that certain dilemmas are generated when reading responsibility against complexity science, at least as represented by the themes selected for discussion here, and when reading both with educational considerations.

What forms and meanings has responsibility in an emergent universe?

First, a central problem is the application of complexity science, designed to explain phenomena and shifting patterns in the natural world, to socio-cultural systems. This critique is by now rather commonplace so a brief summary may be satisfactory. While complexity science has focused on physical movements and links among objects and actors, human systems are very much determined by interpretive movements among perceptions, symbols, identities, and meanings. Therefore relations among humans cannot be explained solely in terms of physical motion and change because they entail emotion, desire, power, and ethics. Applications of complexity science to social questions have been engendered through a metaphor of complexity, argue critics such as Houchin and McLean (2005). That is, the images of emergence, selforganisation, uncertainty, flows and so forth can and have been treated as representations of desirable patterns, then projected interpretively onto realist social systems to produce notions of positive human interconnections, inventive adaptation and continuous learning. While such metaphors hold a certain romantic appeal they in fact correspond only faintly to either their scientific progenitors or to the forces that actually influence social systems. However, Osberg and Biesta (2007a) counter that a poststructural or philosophical approach to complexity - in contrast to the metaphorical appropriation of complexity notions - can open what they consider to be a politically conscious explanation of human systems and relations. In such an approach to complexity, the focus is not upon patterns of actors and action but upon enacted knowledge which is 'neither a representation of something more 'real' than itself, nor an 'object' that can be transferred from one place to the next ... Knowledge is understood, rather, to 'emerge' as we participate in the world' (p.2).

Even if we accept that human social systems can be adequately addressed using a philosophical approach to complexity, are notions of responsibility, understood as either response or obligation, at all compatible with a complexity universe of flows and emergence? That is, while complex systems are identifiable and bounded, they are continually dynamic, changing and adapting in novel unpredictable patterns through myriad interplays within and among various systems occurring in an environment. Bai (2003) asks, what does it mean to be a human being, a person, in a relational universe? How does one being relate to another, and what is it for relational beings to have responsibility towards each other? Since educational processes fundamentally shape particular conceptions of humanity and social behaviors among learners (and teachers), these are central questions. Complexity itself neither implies nor encourages any 
'oughts' for behavior among its elements, and educators are left to map their own answers to the central question: How should we act in a relational universe? Clark (2003) argues that we need an ethics to negotiate and regulate conditions of uncertainty. This may be particularly pressing when we believe all of our actions are so interconnected as to pose profound implications for the system's emergence. For educators, who are also pressed in the thick of emergence to form judgments that affect students immediately and the community eventually, the question of responsibility is about how to approach such judgments when one cannot know what shapes are emerging, let alone assess them as desirable or undesirable.

The notion of emergence also invites considerations about what sorts of responsibility might arise out of entanglement in volatile processes, and what forms of novelty and surprise might arise out of response and responsibility in emergent processes. If actors simply respond spontaneously, care for the vulnerable may or may not emerge: indeed, social history has proven quite the opposite. And accountability, which rests on notions of personal and collective responsibility, remains an important if currently over-rationalised dynamic in educational purpose and delivery. What are the implications of responsibility when causes cannot be disentangled from effects? Finally, emergence requires conceptualisation of responsibility in an inter-objective universe, where the flows connect humans and non-humans. How do we understand responsibility to and among objects (and tools and discourses), and from objects to humans?

How can alterity and care for others be understood?

Second, if there is no autonomous, determinate individual separate from interactions and relations embedding and co-specifying all actors within the webs of a complex system, who takes responsibility for whom? Bai (2003) is one of the few who have undertaken close examination of ethics in complexity science. She argues that when we view the other as an 'inter-penetrating matrix of relationships ... an inter-being with the self' (p. 9), we think not in terms of controlling the other but as establishing a union from which can emerge a desired pattern of relation for both parties. These relations are dynamic, non-linear, and hence nondeterministic. In a conception very similar to Varela's, Bai describes being as an 'interpenetration' of elements and forces that cannot be considered as separate or separable (Bai, 2003, p. 10). This conception implies that there is no distinct other to which a subject responds, and therefore no singular subject that discerns distinction and need, and formulates a response.

Yet emergence and self-organisation depend upon diversity and interaction among diverse parts. In educational contexts, as Davis and Sumara (2005) argue, diversity is critical to ensure uncertainty and continual improvisation in the group, from which emergence and resilience are generated. For diversity and difference to exist, there must be distinction among elements: there must be alterity. And where there is alterity there must be singularity. But equitable positionings, or symmetry, among singularities is hardly reasonable to assume; indeed, social science has established the ubiquity of asymmetry in social systems. Recognition of these differences both cultural and individual, as Taylor (1994) argued from a political perspective, is absolutely critical as the beginning of mutual interdependence. Even when subjects are considered to be partially singular but connected in relationship, we are led to ask what compels these relations, these inter-connections, beyond chance encounters? Psychoanalytic theorists show how humans in 
educational pursuits of knowledge are influenced by desire, manifested as attraction and repulsion (Britzman, 1998). Social theorists show the influences of dominant cultural discourses, positional interests, economic and social asymmetries that govern behaviors and connections within social systems. Arguably, complexity science has failed to account for these influences. Asymmetry begs the ethico-political question of responsibility among parts, which cannot be answered easily when the default position is to an ontology of inter-penetration.

What is desirable and what desires are possible in self-organisation?

Education begs the question of what constitutes a desirable future, or even a desirable or healthy system. Complexity science, however, does not indicate what is desirable beyond the survival of the system in some form - either to ensure maximum benefit for greatest number, to honour humanity, or to adhere a priori to rational ethical laws or virtues. Complex adaptive systems in the natural world do not necessarily care for their vulnerable parts, nor do they seek equity among parts, or arbitrate asymmetries. Many systems left to self-organise emerge as destructive, dehumanising, even hierarchical systems which shut down rather than promote creativity. Indeed, the exercise of human desires, positional interests and power relations within any social systems often produce order and control rather than emergence The few empirical studies available of attempts to induce complexity among social organisations report discouraging outcomes. Houchin and Maclean (2005) for example, in a longitudinal study of four organisations, showed that using complexity concepts of decentralised self-organisation and promoting emergence through diversity, feedback and interaction actually induced anxiety that created fragmentation and reinforced power differentials. They concluded that self-organisation can actually favour the powerful, marginalise or destroy the weak, and induce actions that cause destruction or degradation of some elements. One response to this could be that complexity was not actually created in these cases, but such an assessment implies that 'true' complex adaptive systems are manifestations of pre-existing ideal forms, which contradicts the central tenets of self-organisation and diversity. But the other issue of self-organisation and creative adaptation, as Blanchot $(1995$, p. 2,48$)$ points out, is that what may be for some an act of creation, an irruption of novelty, is for others a 'disaster' - loss, disorientation, a radical unworlding. In fact, destruction and destabilisation are necessary in continuous organising processes of systems operating far from equilibrium. This disequilibrium promotes and is promoted through experimentation and play, but also through rupturings, disasters, and deaths. What position can responsibility take in such conditions? How can an educator act, and towards what educational purposes?

\section{Re-thinking educational responsibility in complexified education}

Writers who have applied ideas from complexity to education in school as well as work environments tend to characterise the dynamic non-linear interactions as benign encounters of co-specification out of which new creative possibilities emerge. Kauffman (1995, p. 30) describes the world of complexity as one of 'enchantment' marked by 'gentle reverence for everchanging and unpredictable places in the sun we craft ever anew for one another'. Bai (2003) writes of universal beneficence and generosity that inheres in the relational world of non-linear causality. Davis (2004) claims that complexity discourses 'advocate an attitude of mindful participation in the unfolding of personal and collective identities, culture, intercultural space, 
and the biosphere' (p. 176). Davis and Sumara (2005) encourage teachers to induce emergence in classrooms by creating conditions that have been associated with complex adaptive systems: diversity, interaction, redundancy, decentralisation, and feedback. In this invocation educators insert themselves as responsible agents into a system, manufacturing conditions to produce effects based on a view of a desirable future - continuous adaptation, creative improvisation, collective emergence of knowledge and action, and so forth.

But when such a view is constructed entirely within complexity science, its proponents may be tilting towards a certain totalisation in the same way that those arguing for social justice impose a view of structural oppression and desire for social responsibility on education. In both cases as for us all, a moral imperative is at work, reminding us to question the self-reflexive awareness of the theorists' own positional interests. What explicitly is the view of educational responsibility, and how can this view be justified within its own theoretical parameters? When educators take up a responsibility to achieve an ideal social future through educational practice, they are not only presuming to impose a particular moral imagination on the emergence of things but also, recalling McWilliam and Lee (2006), assuming that learning processes can and should serve as a channel to realising these imagined futures. These assumptions underpin a sort of pedagogical audacity (Fenwick, 2005) upheld through appeals for educational purposes rooted in some notion of a social good. Whether driven by messianic ideologies of equity and social justice or notions of holism and 'mindful participation', whether justifiable or not in terms of prevailing community desires and priorities, the question returns to how learning and educational processes are understood in such purposes. As Osberg and Biesta (2007a) point out, when education is conceived as a process of shaping subjectivities - socialising particular minds, bodies and knowledge in a process of 'planned enculturation' - the possibilities of learning are truncated. The possibilities of what a human being can become and what knowledge and activity might emerge through educational processes are reduced and contained in pre-determined and ultimately reproductive conceptions.

Yet to eschew the insertion of responsibility in educational processes for fear of controlling or colonising others is, Biesta (2006) argues, to be irresponsible. The educator must do something to fulfil responsibility as educator, must bring about something, must act purposefully. So, given these issues, what can educational responsibility mean in a 'complexified' educational vision?

Immediacy - focus on the imminent

One place to start is with a little book entitled Ethical Know-How by Francisco Varela (1999). While Varela is speaking from a theory he and colleagues called enactivism, his tenets of emergence, inter-connectedness through co-specification, and self-organisation are closely aligned with the themes of complexity science adopted for this discussion. His work is frequently referenced by educational writings that incorporate complexity science (e.g. Davis, Sumara and Luce-Kepler, 2000). Varela's arguments are not unproblematic: indeed, in trying to fashion a complexity-rooted explanation of ethics, he appears to end up drawing from Buddhist ideas that then are imposed upon complexity science as though they have emanated naturally from its own precepts. 
Varela argues that ethical knowhow is enacted in spontaneous everyday responses - 'immediate coping' rather than through acquiring and applying ethical rules. He claims that despite our illusions of reasoned choice and intentional action, 'we always operate in immediacy in the world' without deliberate pre-reflection that effectively governs our behavior. Therefore ethical learning, for Varela, is about discovering how one acts through immersed with others in the everyday: that is, reflecting on one's ways of participating with others and the consequences of these encounters. He eschews the disciplining of behavior towards any pre-determined good, arguing instead for removing barriers to 'natural ethical wisdom' innate in beings, a wisdom that Varela maintains prompts 'spontaneous compassion'.

It is here that Varela indicates what responsibility might mean in a relational, emergent universe. His notion of response focuses upon local encounters, in spatial terms, and his temporal focus is upon the immediate - the spontaneity of connections and immersions unfolding as they are enacted. Varela's emphasis is on the quality of the connection itself, on what is created inbetween and with-in beings in the moments of encounter and interaction.

That Varela is concerned with compassion in these encounters is, however, problematic. Compassion - with passion, especially suffering with - invokes emotions of ardency, abandon and desire as well as empathetic caring, even solidarity with the other. However, Varela does not clarify why this quality emerges or is desirable, nor what prompts compassion among beings - or even the relation of compassionate response: whether mutual or directed towards the one in need, conditional or unconditional. A problematic equivalency among beings appears to be assumed, as though positionality is not at issue. A further problem is Varela's conception of spontaneous response. While this may describe an individual's experience of responding or even a casual viewer's perception of responsiveness, it does not address the complex relations at play. What causes the response to this one and not that one? Why a response in this way and not some alternative? The source for Varela's focus on compassion is also ambiguous. It derives not from complexity science's explanations of behaviors across systems. Indeed as Varela develops the idea with reference to 'a transcendance of ego' and 'freedom from the 'grasping' desiring I', he seems to be applying moral guidance from some doctrine external to complexity science, in ways that take us back to teaching particular forms of response approved by some pre-determined universal principle of the good.

However Varela's encouragement to attend not to ethical laws but to the responses and connections that emerge in immediate local encounters among beings is helpful, and reminiscent of Bauman's (1993) writings about ethics in a postmodern age. Bauman's analysis can be considered relevant given that complexity science in education has been described as a 'postmodern' approach (Clark, 2001; Davis and Sumara, 2006). Ethical being, writes Bauman, embraces uncertainty, lets go of rational intention, and engages the micro-interactions. Reason will deprive the self 'of what makes the self moral . . That non-calculable urge to stretch towards the other, to caress, to be for, to live for, happen what may' (p.247).

Response - emerging in the 'yes' to the other

This urge toward the other recalls the conception of the ethical subject emerging in encounters with the other proposed by Levinas. For Levinas (1985), responsibility is enacted as a response 
to the 'call' of the other. The other is not an object to be possessed, nor an obligation dictated by ethical rules, but a subject to whom the I is personally and unconditionally responsible. The other precedes the subject, is not constructed or 'recognised' as part of one's conscious ethical obligations. The call is felt as a non-conscious appeal, face to face. Levinas describes this appeal as being held 'hostage' by the other, in subjection. Further, the call is for me, and no other. In this intersubjective ethics, the response is of caring or justice to a call of need from one who is vulnerable, suffering, or otherwise positioned asymmetrically to the one called. Such response is not a rational decision motivated by duty but an immediate bond to the other. In this response the subject emerges:

This charge is a supreme dignity of the unique. I am I in the sole measure that I am responsible, a non-interchangeable I. I can substitute myself for everyone, but no one can substitute himself for me. (Levinas, 1989, p. 101)

Responsibility, then, inheres in the actual relation between human beings. The I apprehends the call of the other and responds: not by appropriating the other, manufacturing, developing, rehabilitating, socialising, or any of the other positions commonly adapted in pedagogical relations - but responding. This position is echoed in Bai's (2003) conception of responsibility in the relational universe, where she explains that a subject does not have relationships, as though it existed as an unchanging entity, possessing connections, whose interaction with the world results in external and circumstantial changes. Instead, 'We are our relationships. We are nothing other than our relationships - with each other, with the world' (p. 23, italics added).

But Levinas avoids dissolving the subject into a universalised matrix of inter-being: 'The strangeness of the Other, his irreducibility to the I, to my thoughts and my possessions, is precisely accomplished as a calling into question of my spontaneity as ethics' (Levinas, 1969, p. 33). The other remains unknowable, outside the totality we may wish to incorporate it into: our relation with the other is a 'relation without relation' (ibid., p. 79). Thus, as Biesta (2006) explains, in Levinas' conception of relationship he shows the singularity of the subject as enmeshed and interdependent while unique and asymmetrical: the unique subject is born in an ethical relationship, not ascribed to an essence; and enacted through participation in the responsibility of that relationship, not through conscious exercise of ethical principles:

What constitutes me as this unique individual, as this singular being, is the point in time (which according to Levinas is actually the very beginning of temporality) at which I no longer deny the undeniable responsibility that is waiting for me. It is the point in time when I say 'yes' to the other, keeping in mind that this 'yes' is always already a response to a 'question' and not an act of recognition that would only bring the Other into existence. The Other exists before me. (Biesta, 2006, p. 86)

According to this view of responsibility, my response to the other, turning to face the call and to say 'yes', is an awakening - both to the uniqueness of me, and to the relation and subjection to the other in which I am already, and have always been, constituted. Therefore theoretically we have a way to understand both alterity and the motive to connect across asymmetry within the flows, emergence, uncertainty and relational self-organisation of complexity science.

Openness - seeking new connections 
Responding to 'calls' of others requires a discernment of these calls to begin with. Karpiak (2000), another educator drawing upon complexity science, writes at length about attunement: the capacity to actively sense other possibilities. This has some resonance with Levinas' emphasis upon a general orientation to connection with the other. Bai (2001) also describes this orientation, which for her comes through an awareness and desire for interconnectedness. Such attunement or orientation to connection presumes an openness. This presumption poses questions about when and to what are elements disposed to open themselves to connection with other elements.

The dynamic of opening is also treated by Deleuze and Guattari (1987). Their emphases on processes, flows across bodies, and complex becomings are consistent with principles of complexity science. Unlike Levinasian ethics modelled on subject-to-subject human relationships, Deleuze and Guattari do not foreground the human, phenomenological subject. In their discussion of processes of becoming, they portray a driving force of creativity manifesting in the desire to seek out new connections. In the resulting excess of energy the self is always open to reconfiguration but also interlinked with the environment in ongoing exchange. The ideal nomad is not characterised by continuous movement but by receptivity and responsive to the dynamics flowing around and through (Deleuze and Guattari, 1987, p. 380-81). This will to encounter and connect is itself ethical: a body opening to others. Such opening, such vulnerability, is a risk. There is always uncertainty as to the resulting possibility or connection bringing harm or creative transformation. But then all generative forces are violent, destroying current existence. Drawing from these ideas, Clark (2003) concludes that to act ethically is to remain attuned, receptive and responsive, working with the forces at hand: the dynamics of the system in which one is implicated. The attunement or opening is not only an acceptance of risk, but a generous orientation: Deleuze and Guattari (1987, p. 277) write that the relations of generosity and generativity are at the heart of becoming and the advent of the ethical. In a resonant direction, Bai (2003, p. 10) emphasises what she calls 'the generosity principle' that she claims animates ethical relations in complexity. This generosity is, suggests Bai, an outpouring, an excess of action, almost a compensation for an under-determinate, non-linear world where one can never know how one's actions have affected/are affecting the unfolding patterns.

Leaping into uncertainty - responsibility without knowledge

While these reflections on a generous orientation and openness to connection help address the question of how we become sufficiently aware to respond to others' call, they still leave open the question of who we are drawn to, why, and with what consequences in a complex universe of asymmetrical beings. One source of assistance here may be Derrida (1995), whose later writings on ethics expanded and reconfigured Levinas' conception of the compelling call to respond to an other unconditionally. Derrida, like Varela, portrays responsibility not as an abstract notion but as an intimate and everyday experience:

Always there is implied involvement in action, doing, a praxis, a decision that exceeds simple conscience or simple theoretical understanding. It is also true that the same concept requires a decision or responsible action to answer for itself consciously, that is, with a knowledge of a thematics of what is done, of what action signifies, its causes its ends, etc. (Derrida, 1995, p. 25) 
In particular, Derrida emphasises that any action of responsibility requires a 'leap into uncertainty', beyond what can be known, beyond the existing laws and norms of responsible behaviour. One main reason for this uncertainty is that one's action is always, in a sense, damaging. This is because of all the other Others that are and must be excluded in responding to the call of a particular Other. The example Derrida dwells upon is drawn from Levinas' own explanations: the near-sacrifice of Isaac by his father Abraham following direction from God. In responding to this call of the Father, Abraham must betray both obligatory paternal bonds and community standards for which such infanticide is unthinkable. As Derrida concludes:'I cannot respond to the call, the request, the obligation, or even the love of another, without sacrificing the other other, the other others' (Derrida, 1995, p 68). The unrealised possibilities in the calls of these other others, and our irresponsibility in turning from them, haunt our every decision and action.

This is why, according to Derrida, our enactments of responsibility must unfold in secrecy, and involve sacrifice. We always sacrifice others to respond to the immediate, and our action of response is far too complex to withstand the judgment of community standards and universal laws, which are always more simplistic than everyday dilemmas. In fact, Derrida cautions that one never 'act in good conscience', following universal principles, because to do so is irresponsible: one simply resorts to generality rather than participating fully in the conflicting calls of the immediate. So, true responsibility consists in oscillating between the demands of that which is wholly other and the more general demands of a community. Responsibility is enduring this trial of the undecidable decision, this interminable experience, where attending to the call of a particular other will inevitably demand an estrangement from the 'other others' and their communal needs, and where closure to the problem is never reached. Whatever decision one may take, according to Derrida, it can never be wholly justified. As Edgoose (1997) points out, the aporia of undecidability alone would result in paralysis and procrastination:

But the aporia of urgency forces this into an instant of hesitation. Between the universal and the particular, as Kierkegaard well knew, one must leap. (p. 276).

And thus this decision is a leap into uncertainty. To act otherwise, to resort to ethical laws or community directives, dissolves one's singularity, one's coming into presence - in presence of this singular other that is calling one forth.

\section{Conclusion}

In this preliminary exploration of responsibility read both with and against themes from complexity science in educational contexts, I have tried to highlight some useful intersections. It appears that reflections on responsibility by Levinas and Derrida are resonant with complexity science in emphasising the importance of relations among beings, and of 'becomings' as generated within these relations, not pre-existing them. What responsibility invokes are questions about just how, when and what beings relate to others in different circumstances. These questions help bring into play the ethico-political dimension that is inherently absent in complexity science, which is one reason why complexity precepts have sometimes proved difficult to apply to social systems fraught with power relations, desire, positional interests, and economic and social assymetries. Considerations of responsibility also illuminate certain silences in complexity science, as it is currently being applied in educational writings, around issues of 
alterity and difference, care for (vulnerable) others, what constitutes a desirable future, and how one should act in a relational universe - all issues that educators must deal with.

But I have also explored some helpful alternatives offered by complexity themes to certain notions of social responsibility that have become rather uncritically embraced in educational theory and practice, particularly in contemporary adult education. Ideas of consciousness-raising, resistance and emancipation - indeed, any moral imperatives driving an educational vision imposed upon others - can be deeply problematic. Complexity challenges these notions to consider webs of relations, interconnectivity, and emergent designs and strategies. To expand upon these themes, drawing from philosophical writings on responsibility, we are led to consider the nature of response to one another among beings, and the consequences of this response. From these writings I have suggested alternative approaches to educational responsibility that remain consistent with complexity themes but that incorporate considerations of power, positionality, language and desire that are key dynamics in human systems. These approaches include focusing on the immediate and imminent, opening to the possibility of connections, attuning to the other's call and responding to it, and leaping into uncertainty by accepting the turmoil of sacrifice and secrets attending one's participation in response.

But to return to the central problem, how does one live and act 'responsibly' in educational practice according to these characteristics or any others while unsettling the very notion of responsibility? Biesta (2006) advises that educators end up living the double: the responsibility of the undoing while doing. This follows Derrida (2005), who writes of being committed to both design and its transgression. The determined pedagogical impulse to control, to change, to rehabilitate, needs to be resisted if new openings and alternatives can flourish. The caring pedagogical relation based on a gaze constructing deficit and improvement can be re-situated to a gaze of response: face-to-face, unconditional. The moral pedagogical mantra of social responsibility can be productively redirected through ontologies of a relational universe where unique subjects are understood to emerge through non-linear flows of responsible relations. Educators might think of doing less rather than more: focus on the immediate, open to possibility, leap into uncertainty, care without knowledge. Biesta (2006) argues that responsibility of the educator:

lies precisely in a concern for the paradoxical - or deconstructive - combination of education and its undoing. ... [W] hat disrupts the smooth operation of the rational community is not necessarily a disturbance of the educational process, but might well be the very point at which students begin to find their own, unique, responsive and responsible voice. This also shows that the responsibility of the educator, the educational responsibility, is a responsibility for something that cannot be known in advance - it is a responsibility without knowledge of what one is responsible for. (p. 68)

Ultimately, what responsibility means for education, from a complexity perspective, is actively living in the aporia - between collective law, the unconditional call of an other, the call of other others - with no certainty about what might emerge or what is right. But still, we can and must act within this undecidability. It may be in our attunement to the imminent, our openness to connective possibilities, and our active response to calls of these possibilities, despite their risk, that we and others may emerge in educational relationships. 
Acknowledgements: I wish to thank the three anonymous reviewers for their thoughtful commentary and suggestions, which have strengthened the paper considerably. All errors are my own.

\section{References}

Bai, H. (2001). Beyond the educated mind: towards a pedagogy of mindfulness, body and mind, (In B. Hocking, A. Haskell \& W. Linds, (Eds.), Body and Mind: Exploring Possibility Through Education (pp 86-99). Vermont, NH: Foundation for Educational Renewal). Bai, H (2003). On the edge of chaos: complexity and ethics. In Proceedings of the First Conference on Complexity Science and Educational Research. (pp. 19-30). Edmonton Alberta: University of Alberta). http://www.complexityandeducation.ualberta.ca/pub03proceedings.htm

Bauman, Z. (1993). Postmodern ethics. (Oxford: Blackwell).

Biesta, G.J.J. (2006). Pedagogy with empty hands: Levinas, education and the question of being human. In D. Egéa-Kuehne (Ed.) Levinas And Education: At The Intersection Of Faith And Reason. London: Routledge.

Biesta, G.J.J. (2006). Beyond learning: democratic education for a human future (Boulder Colorado: Paradigm Publishers).

Blanchot, M. (1995). The writing of the disaster (trans. Ann Smock). University of Nebraska Press.

Britzman, D. (1998). Lost subjects, contested objects: Towards a psychoanalytic theory of learning. New York: State University of New York Press.

Capra, F. (1996). The web of life: a new scientific understanding of living systems. (New York: Anchor Books).

Clark, N. (2005). Facing disaster: dynamic instability and exorbitant ethics. Paper presented to the Complexity, Science and Society Conference, University of Liverpool, September 12, 2005.

Cutright, M. (Ed.) (2001). Chaos theory and higher education: leadership, planning and policy (New York: Peter Lang).

Davis, B. (2004). Inventions of teaching: a genealogy. (Mahwah, NJ: Erlbaum).

Davis, B, Sumara, D J, \& Luce-Kapler, R (2000). Engaging minds: learning and teaching in a complex world. (Mahwah, NJ: Erlbaum).

Davis, B., \& Sumara, D.J. (2005). Challenging images of knowing: complexity science and educational research. International Journal of Qualitative Studies in Education, 18, 3, 305321.

Davis, B., \& Sumara, D.J. (2006). Complexity and education: inquiries into learning, teaching and research. (Mahwah, NJ: Erlbaum).

Deleuze, G., and Guattari, F. (1987). A thousand plateaus: capitalism and schizophrenia. (Minneapolis: University of Minnesota Press).

Derrida, J. (1990). Force of law: the mystical foundation of authority, trans. Mary Quaintance. Cardozo Law Review 11, 919-1070.

Derrida, J. (1995). The gift of death. (Chicago and London: University of Chicago Press).

Doll, W. E., Fleener, M.J., Trueit, D., and St. Julien, J. (Eds.) (2005). Chaos, complexity, curriculum, and culture: a conversation (New York: Peter Lang). 
Edgoose, J. (1997). An ethics of hesitant learning: the caring justice of Levinas and Derrida. Philosophy of Education, 266-274.

Fenwick, T. (2006). The audacity of hope: Towards poorer pedagogies. Studies in the Education of Adults, 38 (1), 9-24.

Gibbs, R. (2000). Why ethics? signs of responsibilities. (Princeton University Press).

Haggis, T. (2007). Conceptualising the case in adult and higher education research: a dynamic systems view. In J. Bogg, J. and R. Geyer (Eds) Complexity, Science and Society (Oxford: Radcliff).

Levinas, E. (1969). Totality and infinity: an essay into exteriority. (Pittsburgh: Duquesne University Press).

Levinas, E. (1981). Otherwise than being or beyond essence. (The Hague: Martinus Nijhoff).

Levinas, E. (1985). Ethics and infinity (Pittsburgh, PA: Duquesne University Press).

Levinas, E. (1989). The Levinas Reader (ed. Seán Hand). Cambridge: Basil Blackwell

Houchin, K. \& MacLean, D. (2005). Complexity theory and strategic change: an empirically informed critique, British Journal of Management,16, 149-166.

Kauffman, S. (1995). At home in the universe: the search for laws of complexity (London: Penguin).

Karpiak, I. (2000). Evolutionary theory and the new sciences. Studies In Continuing Education, $22,1,29-44$.

Laidlaw, L. (2005). Reinventing curriculum: a complexity perspective on literacy and writing (Mahweh, NJ: Erlbaum).

Martin, I (2003). 'Adult education, lifelong learning and citizenship: some ifs and buts', International Journal of Lifelong Education, vol 22 (6), pp. 566-579.

Maturana, H. \& Varela, F. (1987). The tree of knowledge: the biological roots of human understanding (Boston: Shambhala).

McWilliam, W. \& Lee, A. (2006). The problem of 'the problem with educational research'. The Australian Educational Researcher, 33 (1), 43-60.

Orford, A. (2005). Critical intimacy: Jacques Derrida and the friendship of politics. German Law Journal: Review of developments in German, European and International Jurisprudence, 1, $6,31-42$.

Osberg, D. \& Biesta, G. (2003). Complexity, representation and the epistemology of schooling. In Conference Proceedings of the First Conference of Complexity Science and Educational Research (Edmonton, Alberta: University of Alberta). www.complexityandeducation.ualberta/ca/pub03proceedings.htm

Osberg, D. (2005). Redescribing 'education' in complex terms. Complicity: An International Journal of Complexity and Education, 2, 1, 81-83.

Osberg, D. \& Biesta, G. (2007a). The emergent curriculum: Navigating a complex course between unguided learning and planned enculturation. Journal of Curriculum Studies, published online 11 October 2007, DOI: 10.1080/00220270701610746. Retrieved from http://www.informaworld.com/smpp/content?content $=$ $10.1080 / 00220270701610746$

Osberg, D. \& Biesta, G.J.J. (2007b). Beyond presence: epistemological and pedagogical implications of 'strong' emergence. Interchange, 38(1), 31-51.

Prigogine, I. (1997). The end of certainty: time, chaos, and the new laws of nature. (New York: Free Press). 
Stacey, R. D. (1995). The science of complexity; an alternate perspective for strategic change processes. Strategic Management Journal, 16, 477-495.

Stacey, R.D. (2005). Experiencing emergence in organizations: local interaction and the emergence of global pattern. (London: Routledge).

Taylor, C. (1994). The politics of recognition. (In A. Gutmann (Ed.), Multiculturalism: Examining the Politics of Recognition (Princeton University Press).

Van Manen, M (2000). 'Moral language and pedagogical experience', Journal of Curriculum Studies, vol. 32 (2), 315-327.

Varela, F. J., Thompson, E., \& Rosch, E. (1991). The embodied mind: cognitive science and human experience. (Cambridge, MA: MIT Press).

Varela, F. J. (1999). Ethical know-how: action, wisdom and cognition. (Stanford, CA: Stanford University Press).

Waldrop, M. Mitchell. (1992). Complexity: the emerging science at the edge of order and chaos. (New York: Simon \& Schuster).

Wildemeersch, D., M. Finger, M. \& Jansen, T. (Eds.) (2000). Adult education and social responsibility, second edition. (New York: Peter Lang). 